\title{
Mind Mapping as a Teaching Tool in Higher Education Language Learning Settings
}

\begin{abstract}
Many instructors willing to undertake teaching in a foreign language are progressively noticing the need to improve the quality of classroom discourse and lecturing styles, so that students can capture and process the information delivered more efficiently. Mind-maps can be an important and effective asset to anyone who wants to learn a language. They are considered to be a great way to brainstorm and generate more ideas. They help to create a number of small ideas from one big idea, to see how different ideas could be connected together and to create a plan of action. They break from the traditional way of thinking when learning, and therefore they encourage creativity - and this can be achieved only when there are no restrictions, criticism and judging. The result should be a very creative, new solution to problems, a generation of original, relaxed and informal ideas. The article demonstrates how mind mapping technique can be used to improve language skills: reading, writing, speaking, and listening in higher education settings; moreover, it concerns positive and negative aspects of the use of mind mapping, purposes it may serve, implications, suggestions, and recommendations for mind mapping strategies for teachers and students.
\end{abstract}

\section{Keywords:}

mind-mapping technique, teaching tool, language skills, research, higher education settings

1 Grigol Robakidze University, Georgia. 


\section{INTRODUCTION}

In contemporary higher education settings teaching English at Non-English Department should ideally provide two types of syllabi - English for Academic Purposes and English for Occupational Purposes - since students need English to prepare themselves as students with their own duties and/or responsibilities, and they also need to be prepared with English for Occupational Purposes based on their own disciplines. However, at the level of applications, the teaching process raises a number of issues; it even often leads to conflicts among the aspects influencing the success of learning. Those aspects are the limited number of credits for English classes, the students' low level of knowledge of the language but high expectations, the number of students in class, readiness of the instructors to teach English using an ESP, EAP, or EOP approach, etc. Mind mapping (MM) has advantages in improving students' English ability. The technique could be one of the solutions for the improvement of the quality of teaching English, since its application is capable of generating active, creative, effective (meaningful), and joyful learning.

\section{ESSENCE OF MIND MAPS}

Mind, brain or web maps (Buzan, 1986, 2002), either in the form of spidergrams or concept diagrams, are shown as especially prominent in the assimilation of complex notions. Through the spatial dimension (i.e. through the contrasts of distance/closeness, centre/periphery and the use of the page along the horizontal and vertical axes with left/right and top/bottom positioning) they highlight the relationships between and among concepts, starting from the centre with a knowledge node or key idea and expanding outwards in multiple directions by means of lines and arrows (i.e. branch-outs) that indicate the causal and hierarchical relationships connecting the various subtopics and aspects. Occasionally they may employ key words, images and even mathematical symbols to label or illustrate those relationships and thus make them more visible and easier to learn.

Mind maps can be considered valuable multimodal tools reflecting critical thinking and encouraging continuous learning and the use of diverse cognitive channels (visual and verbal). Mind map involves personal analysis, synthesis and evaluation much more than linear and narrative notes: some items are excluded as a result of selecting others, and the conceptual bonds and relationships displayed and their representation result entirely from the learner's choices and decisions. 
Kress and his team (2001, p. 101) perceived a great deal of variation in mind maps even though students had been given the same instructions and material resources to produce them and had attended the same series of lessons. By and large, such versatility had to do with differential understandings of the topic, divergent interests and aesthetic preferences which showed in the means of composition and directionality. That is, some maps used boxes, others circles, lines and arrows that could be thick or thin, long or short, bold (to indicate modality) or not, solid or dotted. A few resorted to full sentences and mathematical signs, whereas the majority made use of succinct keywords. And there were radial, circular, left-right and top-bottom organizations to depict narrative and descriptive data.

Mind maps are therefore open semiotic systems that help teachers to get to know their students better, which enables them to opt more accurately for one methodology or another. As for the role of mind-mapping as an agent of continuous learning, it enhances the idea that the acquisition of knowledge is a transformative process of sign-making: students reshape what they read, see or listen to and may disassemble and reassemble those contents to make them newly meaningful.

\section{PURPOSES MIND MAPPING CAN SERVE}

Mind maps may prove extremely convenient. In the first place, they are pointdriven notes since they consist in a concise representation of basic concepts and relationships (e.g., cause and effect, classification, composition and exemplification), which ramify progressively and are in turn the major constituents of science and technology lessons. Secondly, branching-outs are deemed to be more memorable than linear (i.e. vertical listings) and propositional (i.e. narrative) notes because of their visual impact, despite the headings, numberings, underlines, indentations and abbreviation symbols inherent to these two conventional methods. Oxford (1990, pp. 17-19) underscores the importance of memory strategies (i.e. of grouping and associating, as well as of using images) to create mental linkages, and of cognitive strategies to analyze, reason and build a structure for the informative input and output. Thirdly, mind-mapping does in fact activate many of the micro-skills necessary for academic listening enumerated by Richards (1983): the identification of purpose, scope and topic, of the connections between ideas, of the role of discourse markers and key lexical items, or of digressing moves, among others.

Some undeniable advantages of mind-mapping are: it improves confidence in learning abilities and makes them receptive to learning; ideas are better organized, 
associations are visual; new ideas can easier expand around the central idea by adding new topics and sub-branches; connections between ideas and concepts are a lot handier in a visual arrangement; it is easier to learn when seeing the whole picture; mind maps are easy to review, and regular review reinforces memory and creative thinking; communication is effective, clear, concise and live; the brainstorming of ideas and thoughts are appropriately judged. Mind mapping visualizes thought; it helps build up confidence and consolidate student-student as well as student-teacher collaboration; it increases the whole world of ideas explored and connected to the topic, especially before reading, writing or listening activities; it is great for team building and group work practice; it helps students see the results of their efforts and thus English becomes tangible, comprehensible and meaningful to them.

\section{SHORTCOMINGS OF MIND MAPPING IN THE LANGUAGE CLASSROOM}

Not being blinded by the powerful advantages mind-mapping offers, as stated above, we also need to admit the disadvantages mind-mapping brings about in the EFL classroom. Students may think it is time consuming. However, this must appear to be so only in the beginning. There is one solution to cope with it: any students who get involved in mind-mapping technique to improve their leaning need to practice regularly. In other words, the more the students use the technique, the easier it becomes. Another disadvantage in mind-mapping technique is that it uses many images, symbols, and colors. As students need to use colored pencils or crayons, they might feel uncomfortable to know that there are students out there writing in their notebook. Moreover, not all students are good at drawing and coloring. It appears to be awkward to force all students to draw images and symbols and color them when making a mind-map.

\section{MIND MAPPING IN TEACHING READING}

Mind mapping has a wide range of usage: from reading books and figuring out main ideas and concepts, to business meetings, planning compositions, sorting out family problems, expanding a topic to be studied.

To be able to produce comprehensive and meaningful mind map, the students should be trained continuously to do step by step procedures. There are a number of software packages that can be used to create mind maps on a computer. 
With the availability of online Mind Mapping tools, it is now even easier to capitalize on the opportunities discussed above. Remember, students have grown up with technology more so than you so introduce them to the technology and let the possibilities fly!

Through mind mapping students will be able to take notes on the important points, classify or summarize them, and link relationships among the points. If it is practiced continually in teaching and learning of reading, it can improve students' ability in comprehending texts quickly and comprehensively. Mind mapping avoids students from just copying the information from the text, improves their creativity in expressing ideas, makes them get used to summarizing as needed in reading academic textbooks. Having just the key words rather than sentences in the mindmapping notes will make learning more internalized and more creative; therefore, learning will be more effective, meaningful and well-organized.

After completing the mind map, the students should be trained again to reexpress the content of the passage based on the result of their mind map. They are not allowed to look back to the passage. It is important to check whether they understand their notes or not. They will try to use their own words to re-express - this will make the learning more challenging for them. This practice will also train students' memory for retaining important information.

A study on the use of mind-mapping technique to improve reading comprehension ability was conducted by Siriphanic \& Laohawiriyanon (2010). The results of the study show that, after teaching the mind-mapping technique, the majority of the students improved their reading ability; English reading comprehension post-test score of students was higher than the pre-test one; most students were satisfied with their own reading comprehension ability; they enjoyed working in a group and agreed that mind-mapping technique was a useful technique and can be applied to non-English subjects. It also revealed that the students felt satisfied with their progress achieved through the use of the mind-mapping technique. Finally, the students also showed excitement when getting involved in teaching and learning process in which the mind-mapping technique was used.

The mind-mapping technique can be used to train students' ability in finding out accurate information (main and supporting information), note-taking and organizing ideas, etc. The teaching and learning process can start from (a) Reading the passage and note-taking, (b) Swapping information from the result of mind map, (c) Checking information, (d) Retelling Information, and (e) Summarizing and Translating. 


\section{MIND MAPPING IN TEACHING WRITING}

In the process of writing, the role of mind mapping can be described as follows:

1. To arouse motivation to write: after finding a topic, students can start from anywhere and do not have to be afraid of making mistakes;

2. To get ideas gathered: by jotting down anything come up in their mind they get ideas together as well;

3. Planning and outlining: by drawing the associative lines they can plan their future composition and it is also possible for them to directly give numbers or other signs on the lines or words;

4. Making notes: from the mind map, the students can choose and then sketch the figure of their composition;

5. Making a first draft: the students can use notes from the previous step or they can directly compose a draft based on the mind map;

6. Revising, re-planning, redrafting: they can easily put side by side their draft and their mind map, then adding or omitting part of the draft, and even rearranging the draft;

7. Editing and getting ready for a final product: the revised draft can once again be put side by side with the mind map to check, choose and select which one should be omitted, added, rearranged to obtain the final product (Suyanto, 2010).

It seems that the actual process of writing (rather like the process of speaking) helps us to learn as we go along. This learning style is effective as some students are fantastically quick at picking up language just by looking and listening. Last but not least is understanding writing as a skill: by far the most important reason for teaching writing is that it is a basic language skill, just as important as speaking, listening, and reading. Students need to know how to write letters, how to put written reports together, how to reply to advertisements and increasingly, how to write using electronic media.

Having an organized display of information from the outset of the writing process may help some students, as it is more easily converted into a draft, whereas in brainstorming, random recording of ideas might lead to problems with the structure of students' texts. As Alamsyah (2009) explained, mind maps work well as their visual design enables students to see the relationship between ideas, and encourages them to group certain ideas together as they proceed. Mind maps work especially well when created in groups, since the discussion aids the production of ideas, and makes the task livelier and more enjoyable. 
The research on teaching spelling skills with mind-mapping software conducted at King Saud University by R. Al-Jarf (2011) concludes that through a graphic depiction of words, these mind maps build upon what students know to help them see relationships with newly introduced phonic categories. Students develop related rather than isolated knowledge of phonetic rules and develop skill in differentiating phoneme-grapheme associations in spoken and written words. These mind mapping strategies have been reported to improve word and concept knowledge as well as comprehension across grade levels, in a variety of content areas, and with a variety of learners, including struggling ESL and learning disabled students. In those studies, mind mapping enabled students to better organize, prioritize, and integrate material presented in a course. Surveyed students also perceived mind mapping (MM) as an entertaining and interesting approach and thought that mind mapping enhanced their learning. Most students preferred individual MM; some preferred group MM. The teacher enjoyed using MM and thought that it fostered student motivation in learning science. Most of the students surveyed appreciated its use for recall and creative thinking, although some prefer a top-to-bottom, linear outline approach.

\section{MIND MAPPING IN TEACHING SPEAKING AND LISTENING}

Mind maps can be designed and applied by teachers to face one of the most important challenges in the teaching of foreign languages: enabling learners to understand the target language and communicate ideas naturally, meaningfully and assertively.

Teaching vocabulary is the most challenging part of the teaching task as most of the times we have to do with students that have already acquired basic, everyday vocabulary and grammar; the next level is to master the specialized vocabulary. It can be boring, yet, a well set up and well executed case study, role-play or discussion can be a motivating and stimulating lesson for both students and teacher.

Mind mapping is inspirational at the beginning of the class, when first tackling the topic; communication is improved, topic is easier and enlarged, the presentation becomes more interactive, ideas are easily conveyed and the feedback clearly demonstrates the understanding of the topic and the acquired expanded vocabulary items. Students are really challenged to come up with new ideas on the concept elicited, as the method creates a competition environment, highly effective for learning new vocabulary and fluently practicing speaking and listening.

Mind mapping is the natural follow-up when the ideas produced are classified for a better use. When employing them, students not only take active part in the 
learning process, but they also see the results of their efforts and thus learning English becomes entertaining, meaningful, even tangible to them.

Foreign language teachers can design and use "Mind Maps" in their classes to scaffold listening and reading comprehension, develop the learner's oral fluency, empower the learner, foster a sense of self-efficacy and consequently maximize the learner's autonomy.

According to McLean (2003), teachers use four motivational drivers: engagement, relevant and meaningful curriculum, structure, and autonomy. The teacher starts by engaging the learner by choosing a relevant and meaningful curriculum. Then, the teacher provides clarity by stating clear goals and revealing a structure which gives the learner a sense of security. Lastly, by constantly being shown their progress, the learners build a sense of self-efficacy and self-determination, which empowers them and contributes to their developing autonomy. Sentence structure, and especially that of the English language, can be confusing. Mind maps bypass this by “chunking” language - using words and short phrases instead of sentences. Experiencing language as individual words and phrases, connected spatially, accompanied by meaning-laden images or icons, can be a lot easier that seeing those same words embedded in sentences and paragraphs. And building a mind map can be a wonderful collective adventure. Mind mapping tends to draw out the more bashful students. They can call out a word or short phrase, and watch as you add it to the map. There is something almost magical when students can see with their own eyes that their ideas are taken seriously and made part of the collective document. They feel listened to. They feel like they are contributing. And because the students are building the mind map together, their understanding grows as the map grows. Since they are part of a process, they become invested in the process. They ask questions; they seek or make clarifications. They are engaged in the process of speaking/listening and, therefore, learning.

Mind maps can be applied even to teach grammar. Grammar is tough even for native speakers. Despite hearing the language from an early age, grammar is not always taught as its own curriculum in schools, and what is picked up in everyday life is not always correct. Presenting basic grammar as a mind map breaking it down into eight branches, and then breaking down each branch a bit further, despite the chronic linear thinking issue, is quite easy to understand. It might be a useful tool in the classroom. 


\section{MIND MAPPING STRATEGIES IN THE LANGUAGE CLASSROOM}

Leyden at examtime.com suggests ten mind mapping pre- (planning, organizing), inside (teaching, handouts, presentations, creativity, learning), and outside (collaboration, assessment, comprehension) class strategies:

Whether it is lesson plan, design of the class curriculum for the school year or planning an assignment timeline, mind maps give a clear and visual overview of what needs to be covered. For a person who regularly jots down ideas and thoughts, mind maps are the perfect tool to create structure and organization of a topic.

Online mind maps can be used in class to brainstorm and generate discussions. They can easily be printed and shared with students. A brilliant way to develop student's communication skills is through presentations. However, students can easily become bored listening to other speakers. Mind maps act as visual information providers and encourage the audience to engage with the material that is being presented. Mind maps have been embraced in the realm of education as a learning tool which helps students reinforce knowledge by making connections between different areas and delving in-depth into an area.

Students can easily work together on group projects or assignments using free online study tools where they can share a teacher's or their own mind map with friends or a group of people. A great way to use mind maps for assessment is to ask students to express their ideas about a topic in a mind map before and after a class. Students will retain the information better and it will also reassure teachers that students remember and understand the knowledge. Analyzing study material by reflecting on what has been learned is key to fully comprehending new information.

Finally, according to Casco (2010), mind mapping as a tool in teaching and learning foreign languages:

Engages the learner - The map acts as a playbill announcing what comes next and draws the learner's attention to the topic. Furthermore, the map provides a structure to reduce the learner's anxiety when receiving input through listening and reading and when speaking.

Activates prior knowledge - The use of images and keywords foster recollection of what the learner knows about the topic.

Encourages the learner to ask questions - The map displays clearly what a learner knows and what he does not know about the topic. Images and interrogation marks widen the information gap and incite the need in the learner to find out what he does not know.

Scaffolds reading and listening comprehension - The map is a powerful tool to facilitate comprehension because if offers the learner a global view of what he/ 
she is going to listen or read. Furthermore, the embedded cues contained in the map prompt the learner to form inferences that in turn act as an aid to understanding.

Scaffolds speaking - The map serves as a tool for the learner to organize his thoughts and speech. The different elements of the map can be easily linked and cross-referenced allowing the learner to create a different discourse each time the learner uses the map.

Assesses oral production - The same map implemented at other stages of the language course can be used to get a new sample of the learner's production. By explaining the connections on the map, the learner will show if he/she has acquired new structures and lexical items. The production obtained with the aid of the map will reveal errors providing an information source for the teacher to reflect upon in his/her future practice.

Scaffolds written production - The map originally designed by the teacher and expanded upon by the learner may become the starting point to write a paragraph or an essay on the topic explored.

\section{CONCLUSION}

The right choice of teaching technique can make the teaching and learning process not only run well but also interesting and enjoyable. Enjoyable teaching and learning activities will help students master the material more effectively and efficiently; it will also make the teacher more focused on the necessary things needed for the class. The adoption of mind maps in teaching has grown recently due to the benefits of using mind maps to learn and the availability of free online mind mapping software. Teachers have recognized the value of using mind maps to engage students, encourage their creativity and, most importantly, to teach them how to rather simply memorize the content. Mind mapping technique is a technique which will lead students to be more independent; thus, it is ready to be applied in small classes as well as in big ones. It is simple, fun and arousing creativity. That is why it is recommended for teachers to apply it in their class.

\section{References:}

Alamsyah, M. (2009). Kiat Jitu Meningkatkan Prestasi Dengan Mind Mapping. Yogyakarta: Mitra Pelajar.

Al-Jarf, R. (2011). Teaching Spelling Skills with Mind-mapping Software. Asian EFL Journal Professional Teaching Articles, 53. 
Buzan, T. (1986). Use Your Memory. London: BBC Publications.

Buzan, T. (2002). Cómo crear mapas mentales. Barcelona: Urano.

Casco, M. (2009). The Use of "Mind Maps" in the Teaching of Foreign Languages. Retrieved from: http://www.madycasco.com.ar/articles/mindmaps.PDF.

Kress, G., Jewitt, C., Ogborn, J., and Tsatsarelis, C. (2001). Multimodal Teaching and Learning. The Rhetorics of the Science Classroom. London-New York: Continuum.

Leyden, A. at http://www.teachthought.com/teaching/10-mind-mapping-strategies-forteachers/.

McLean, A. (2003). The Motivated School. Paul Chapman Publishing.

Oxford, R.L. (1990). Language Learning Strategies. What Every Teacher Should Know. Boston: Heinle \& Heinle.

Richards, J.C. (1983). Listening comprehension: Approach, design, procedure. TESOL Quarterly, 17 (2), 219-240.

Siriphanic, P., \& Laohawiriyanon, C. (2010). Using mind mapping technique to improve reading comprehension ability of Thai EFL university students. 